\title{
PATIENTS WITH BREAST CANCER: CHANGES IN BODY IMAGE
}

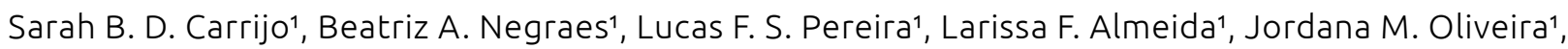
Cláudio C. S. Medrado ${ }^{1}$

1Medicina, Escola de Ciências Médicas, Farmacêuticas e Biomédicas, Pontifícia Universidade Católica de Goiás - Goiânia (GO), Brasil.

Objectives: To describe the major changes related to body image triggered by breast cancer. Methodology: The study consists in a literature review, conducted between March of 2016 and March of 2019, through a research of scientific articles and editorials in the SciELO and Bireme databases, from Medline and Lilacs with the descriptors "breast" "cancer", "body", and "image". Results: The changes brought by breast cancer in the body image are present not only when the woman needs to withdraw the breast, but also in other forms of treatment of the disease. In the mastectomy, the main changes are the body asymmetry, the visual perception, and the imbalance in the distribution of weight. As for radiation therapy, the main change is in the skin texture. In regard to chemotherapy, there may be induced menopause and alopecia. Hair loss affects a woman's identity and safety, as well as triggering the privacy of those facing cancer treatment. The body changes caused by this condition are present even when the organ is rebuilt, as often women do not recognize it as an integral part of their body, requiring some time to adapt to it. Conclusion: Breast cancer is probably one of the most feared by women, which is very much related to the distortion of the body image that this disease causes, affecting the most representative organ of femininity. The body image is a complex mechanism of construction of personal identity, being therefore related to psychic aspects and social relations. Breast cancer causes many changes in body image, involving physical, psychological, and social aspects related to the well-being of the patient facing cancer and, consequently, the effectiveness of the treatment and the overcoming of the disease. 